\title{
Temporal changes in prevalence of diabetes and impaired glucose tolerance associated with lifestyle transition occurring in the rural population in India
}

\author{
A. Ramachandran ${ }^{1}$ C. Snehalatha ${ }^{1}$ - A. D. S. Baskar ${ }^{1}$ S. Mary ${ }^{1}$ C. K. Sathish Kumar ${ }^{1}$ - S. Selvam ${ }^{1}$. \\ S. Catherine ${ }^{1} \cdot$ V. Vijay ${ }^{1}$ \\ ${ }^{1}$ Diabetes Research Centre, M.V. Hospital for Diabetes, WHO Collaborating Centre for Research, \\ Education and Training in Diabetes, Royapuram, Chennai-600 013, India
}

\begin{abstract}
Aims/hypothesis. The rural Indian population is undergoing lifestyle transition due to socio-economic growth. This study was done to determine the temporal changes in prevalence of diabetes and IGT that could have occurred in a rural population in India as a result of the lifestyle transition.

Methods. A cross-sectional study of 1213 AsianIndian subjects aged 20 years or over was done to look for the prevalence of diabetes and IGT using the 1999 WHO criteria. The temporal changes were assessed in comparison with a similar study conducted 14 years previously. The factors associated with the temporal changes were also analysed.

Results. Nearly a three-fold increase in age- and sex-adjusted prevalence of diabetes (from $2.20 \%$ to 6.36\%) was seen in 2003 when compared with a similar study done 14 years before. Prevalence of IGT did not change significantly $(7.44 \%$ in 1989 vs $7.18 \%$ in
\end{abstract}

2003). Improvement in living conditions had occurred during the period, occupational changes were seen, the number of manual labourers had decreased and economic conditions had improved. BMI and waist circumference had increased. After correcting for age, sex and differences in time periods, waist circumference and physical inactivity showed significant associations with the increased prevalence of diabetes.

Conclusions/interpretation. Demographic transition due to improved living conditions in rural India was associated with a three-fold increase in the prevalence of diabetes. Increased upper body adiposity and physical inactivity showed significant association with this phenomenon.

Keywords Demographic transition - Diabetes . Glucose intolerance - Impaired glucose tolerance · Lifestyle changes $\cdot$ Risk factors $\cdot$ Rural population · Socio-economic conditions $\cdot$ Southern India

\section{Introduction}

The large health care burden due to diabetes and other forms of glucose intolerance in India has been mostly attributed to their rising prevalence in urban areas $[1,2$,

Received: 11 November 2003 / Accepted: 28 January 2004

Published online: 28 April 2004

(C) Springer-Verlag 2004

A. Ramachandran (

Diabetes Research Centre, M.V. Hospital for Diabetes,

WHO Collaborating Centre for Research,

Education and Training in Diabetes,

4, Main Road, Royapuram, Chennai-600 013, India

E-mail: ramachandran@vsnl.com

Tel.: +91-44-25954913-15, Fax: +91-44-25954919
$3,4,5]$. A wide urban-rural difference in prevalence of diabetes has been noted in all Indian studies $[6,7]$. In a national survey reported in 2001, the prevalence of diabetes in six major Indian cities varied from 9.3 to $16.6 \%$ with an average prevalence of $12.1 \%$ among the adult population [2]. A concomitant increase in prevalence of IGT was noted. In four out of six cities, IGT:diabetes ratio was greater than 1 , implying the possibility of a future conversion of IGT subjects to diabetes.

Although there was a four-fold higher prevalence of diabetes in urban versus rural areas in southern India, prevalence of IGT was found to be similar in both populations [6]. This was probably an indicator of a similar genetic susceptibility in the population living in different environments. 
India is becoming an industrialised country at a rapid rate and there has been considerable focus on improvement in basic facilities in rural areas, including water supply, electricity, transportation and health care access. The main objective of the present study was to test the hypothesis that lifestyle transition occurring due to improved living conditions in the rural areas might result in increased prevalence of diabetes and IGT. The data were compared with an earlier rural survey conducted in 1989 [6].

\section{Subjects and methods}

In 2003, a rural population was screened to look for the prevalence of diabetes and IGT, and the temporal changes were assessed by comparing the data obtained in a similar study conducted in 1989. The villages selected for both the surveys were classified as rural by the Directorate of Census, Government of India.

A group of villages, 40 miles away from the city limits of Chennai, Tamilnadu, India, was chosen for the present survey. Anticipating a two-fold increase in the prevalence of diabetes from $2.4 \%$ in 1989 to $5 \%$, the number required for the present study was 1064 , with $5 \%$ type 1 error and $95 \%$ power.

The study was conducted in three villages in a 6-month period from February to July 2003. Enumeration of adults aged 20 and above was carried out by our field staff. All eligible members were invited to participate in the screening programme ( $n=1608 ; \mathrm{M}: \mathrm{W}, 807: 801)$. A list of the residents in the villages was obtained from the village administrative (panchayat) office. We sought the help of the village chiefs and social workers in motivating the villagers to participate in the screening programme. Informed consent was obtained from all the participants and the study protocol was approved by the ethics committee of the institution.

The screening was done by house-to-house visit. The proforma containing the details of demography, anthropometry and medical history, as well as educational and social details including monthly family income, occupation, educational status and level of physical activity was completed by personal interview carried out by trained staff. Height and weight were measured and BMI was calculated $\left(\mathrm{kg} / \mathrm{m}^{2}\right)$. Waist was measured as the smallest girth between the costal margin and the iliac crest.

A scoring system was used to quantify physical activity (Appendix 1). Activity levels at work and in household duties were considered per day and the scores were multiplied by the number of days per week engaged in similar activity. The score could vary from 1 to 70 . A similar quantification system had been used in previous studies [2].

In the 1989 survey, a group of villages was selected in which the population consisted mainly of agricultural labourers and represented the low-income group of India. The details were obtained from the Directorate of Census. A total of 1038 subjects (M:W, 520:518; age $\geq 20$ years) were tested. The 2003 survey was not carried out in the same villages as the 1989 survey because the villages studied previously had undergone significant change following the installation of major automobile industry in their vicinity, providing job opportunities for the young village population. Therefore, another group of villages identical to the 1989 study site as recorded by the national census was chosen for the study. The villages had seen minimal rural-urban or rural-rural migration in the previous 14 years.
Similar procedures for sample selection, blood glucose tests, anthropometry and questionnaires for collecting data on socio-economic factors and physical activity were used in the two surveys.

All subjects were asked about lifestyle changes during the previous 14 years, with specific questions on changes in transport facilities, availability of electricity, water and medical facilities, watching television, frequency of meals, access to the city, and personal habits such as smoking and alcohol consumption. The questions were simple and the answers were either "yes" or "no". The data were confirmed by recording the details for more than one family member. Details of education and occupation were recorded.

The subjects underwent an OGTT after an overnight fast. 2-h post glucose (75 g anhydrous glucose load) and blood concentration of glucose were measured in capillary blood using a glucometer (Accutrend sensor; Roche Diagnostics, Germany). Diabetes was diagnosed if the 2-h post glucose was $\geq 11.1 \mathrm{mmol} / \mathrm{l}$, and IGT was diagnosed if the values were $\geq 7.8$ and $<11.1 \mathrm{mmol} / \mathrm{l}$. Similar criteria were used in both the surveys [8]. Comparisons were made with the data collected in the previous survey [6].

Quality control on the blood glucose measurement was checked by measuring the 2 -h plasma glucose values using the glucose oxidase peroxidase method (Roche Diagnostics) in every tenth case. The correlation between the two glucose measurements was calculated using Pearson's correlation method. The regression equation was as follows: glucometer reading $=4.23+0.95 \times$ plasma glucose; $r=0.92 ; p<0.0001$.

Statistical analysis. Prevalence estimations for both the surveys were standardised for age and sex distribution in the 1991 Tamilnadu rural census data using a direct standardisation procedure. Group comparisons were done using the Student's $t$ test or one-way ANOVA, and $p$ values were adjusted for multiple comparisons using the Tukey HSD procedure. Prevalence rates were compared using $Z$ statistics. Chi square test and Pearson's correlation analysis were used wherever relevant. Appropriate statistical techniques were applied for the clustered sampling selection procedures.

To determine the factors responsible for the temporal change in the prevalence of diabetes, the data from the surveys of 1989 and 2003 were combined and multiple logistic regression analysis was done using diabetes versus NGT as the dependent variable. After adjusting for age, sex and differences in time periods, other independent variables were included. They were occupation, physical activity (in quartiles), BMI and waist circumference. Similar analyses were done using IGT as the dependent variable versus NGT. The units for categorisation were age in 10 units, BMI in 5 units and waist in 4 units. Physical activity scores were in quartiles, the first quartile being sedentary. Quartile 4 (strenuous activity) was used as the reference category. Categories of occupation were as follows: (i) manual labourers; (ii) office jobs; (iii) housewives and retired persons; and (iv) persons unable to work. Category (i) was used as the reference. A $p$ value of less than 0.05 was considered significant. Statistical analyses were done using Stata version 7.0 (Stata, Tex., USA).

\section{Results}

In the present study, out of 1608 individuals enumerated, 1213 subjects (M:W, 497:716) with a mean age of $41 \pm 6$ years were available for the study. The overall response rate was $75.4 \%$. The non-responders refused 
a

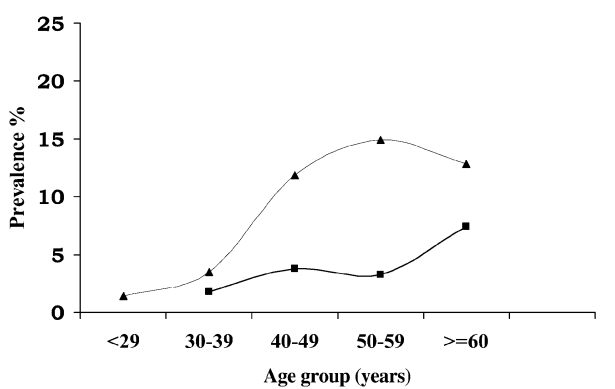

c

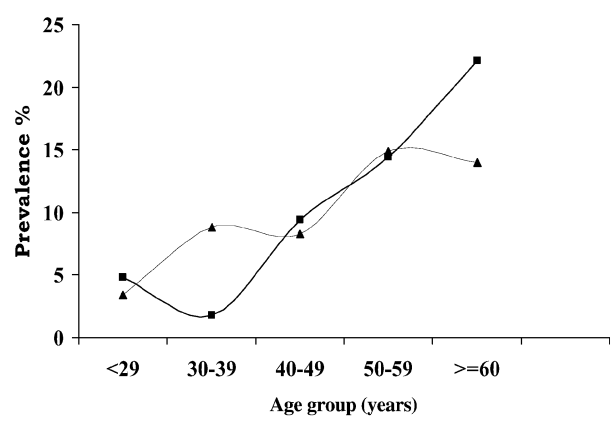

Fig. 1. a, b The age-specific prevalence of diabetes in men and women respectively in $1989(\boldsymbol{\square})$ and $2003(\boldsymbol{\Delta})$. c, d The corresponding age-specific prevalence of IGT in men and women respectively

to undergo any medical screening or were not available at the time that tests were conducted. For the year 2003, the age- and sex-adjusted prevalence of diabetes was $6.36 \%$ (95\% CI: $4.89-7.83 \%)$ and the prevalence of IGT was $7.18 \%$ (95\% CI: $5.36-8.74 \%)$. The corresponding prevalence for diabetes in 1989 was $2.20 \%$ (95\% CI: $1.33-3.06)$, and for IGT it was $7.44 \%$ (95\% CI: 5.82-9.07). The prevalence of diabetes had increased significantly $(Z=-4.83 ; p<0.0001)$ in 2003 , and the prevalence of IGT remained unchanged $(Z=0.175 ; p=0.431)$.

Figure 1 shows the age-specific prevalence of diabetes and IGT in both the surveys. As shown in Figure 1a, b, a significant increase in the prevalence of diabetes was seen over time in both sexes $(p<0.001)$.

Prevalence of IGT remained relatively stable over the period of time (Fig. 1c, d). However, it was noticed that IGT occurred at a younger age than diabetes in both the studies. In the present survey, IGT was more common $(3.7 \%)$ than diabetes $(1.7 \%)$ in subjects aged below 40 years $\left(\chi^{2}=4.22 ; p=0.04\right)$. The corresponding prevalence of IGT and diabetes were $11.2 \%$ and $11.7 \%$ in the subjects below the age of 40 years.

Table 1 shows the comparison of age and anthropometric data in relation to the glucose tolerance status in the present study. As expected, subjects with IGT or diabetes were older and had higher BMI, waist circumference and percentage body fat than subjects with NGT. b

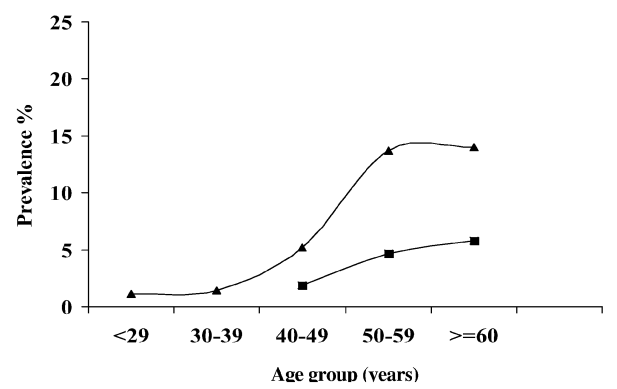

d

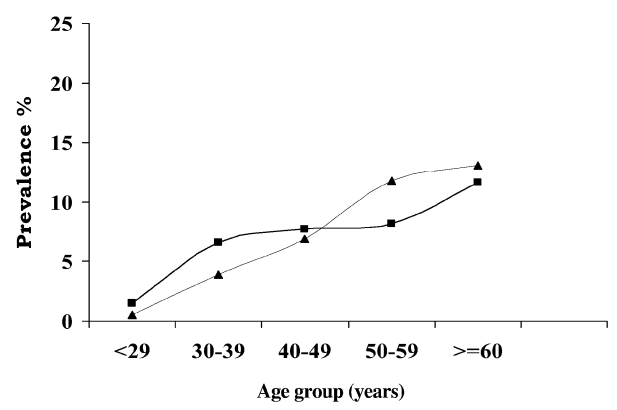

Table 1. Comparison of the anthropometric variables in relation to glucose tolerance status (2003 survey)

\begin{tabular}{llll}
\hline & NGT & IGT & DM \\
\hline Men:women & $416: 633$ & $44: 43$ & $37: 40$ \\
Age (years) & & & \\
Men & $40.1 \pm 15.9$ & $49.6 \pm 16.8^{*}$ & $51.1 \pm 12.3^{*}$ \\
Women & $38.9 \pm 13.8$ & $51.2 \pm 12.6^{*}$ & $54.9 \pm 13.0^{*}$ \\
BMI $\left(\mathrm{kg} / \mathrm{m}^{2}\right)$ & & & \\
Men & & & \\
Women & $20.5 \pm 3.8$ & $21.1 \pm 4.3$ & $22.3 \pm 3.4^{*}$ \\
Waist girth (cm) & & $23.1 \pm 4.5^{* \mathrm{~b}}$ & $23.2 \pm 4.5^{*}$ \\
Men & $79.0 \pm 10.6$ & $82.7 \pm 10.5$ & $86.0 \pm 9.1^{*}$ \\
Women & $75.6 \pm 10.3$ & $82.4 \pm 9.7 *$ & $83.7 \pm 10.2^{*}$ \\
Body fat $(\%)$ & & & \\
Men & $23.3 \pm 7.9$ & $23.9 \pm 7.5$ & $26.5 \pm 8.2^{*}$ \\
Women & $32.3 \pm 10.0$ & $36.8 \pm 10.5^{* a}$ & $37.6 \pm 11.1^{* a}$ \\
\hline
\end{tabular}

Values are means $\pm \mathrm{SD}$; DM, diabetes mellitus; men vs women, a $<0.002 ;{ }^{\text {b }}<0.004$ ( $t$ test $) ;{ }^{*} p<0.05$ vs NGT

Table 2 shows the changes in living conditions that had taken place in the present venue of study in the previous 14 years. There had been significant improvements in transport facilities, medical care, food habits and access to the city. Educational status had improved significantly: $47 \%$ had higher secondary education, among whom $4.2 \%$ had undergone college or technical education. In the previous survey, 95\% had only primary school education. Family income (corrected for the rate of inflation) had improved significantly, and television was watched more frequently. 
Table 2. Improvements in living conditions in the villages in the previous 14 years

\begin{tabular}{lccc}
\hline Factors & Past & Present & $\begin{array}{l}\text { Chi } \\
\text { square }\end{array}$ \\
\hline $\begin{array}{l}\text { Regular use of motorised } \\
\quad \text { transport }\end{array}$ & 86.6 & 93.4 & 31.6 \\
$\begin{array}{l}\text { Electricity } \\
\text { Water supply near residence }\end{array}$ & 50.6 & 95.1 & 605.8 \\
Medical facility & 87.5 & 96.3 & 319.6 \\
Watching television regularly & 23.8 & 78.6 & 732.4 \\
Three regular meals & 57.2 & 70.1 & 42.8 \\
Regular access to city & 54 & 74 & 102.5 \\
Monthly income (Rs)* & $254 \pm 100$ & $1413 \pm 1023$ & \\
\hline
\end{tabular}

Values are percentages unless otherwise stated; a $p<0.001$

$*$ means \pm SD (income corrected for rate of inflation), $p<0.0001$

Table 3. Comparison of results in rural surveys done in 1990 and 2003

\begin{tabular}{lccc}
\hline & 1989 & 2003 & $p$ value \\
\hline$n$ & 1038 & 1213 & \\
Men:women & $520: 518$ & $497: 716$ & NS \\
Mean age (years) & $41 \pm 15$ & $41 \pm 15$ & NS \\
BMI $\left(\mathrm{kg} / \mathrm{m}^{2}\right)$ & & & \\
Men & $17.6 \pm 2.2$ & $20.7 \pm 3.9$ & $<0.001$ \\
Women & $18.7 \pm 3.0$ & $21.5 \pm 4.2$ & $<0.001$ \\
Waist $(\mathrm{cm})$ & & & \\
Men & $71.4 \pm 6.5$ & $79.9 \pm 10.7$ & $<0.001$ \\
Women & $68.7 \pm 8.5$ & $76.4 \pm 10.6$ & $<0.001$ \\
BMI $\geq 25 \mathrm{~kg} / \mathrm{m}^{2}(\%)$ & & & \\
Total & $2^{\mathrm{a}}$ & $17.1^{\mathrm{a}}$ & $<0.001$ \\
Men & 0 & 14.3 & \\
Women & 4 & 19.1 & \\
\hline
\end{tabular}

Values are means $\pm \mathrm{SD} ;{ }^{\mathrm{a}} \chi^{2}, 140.7$

The distribution of subjects according to occupation was as follows: (i) manual labourers, 22.8\%; (ii) office workers, 20.2\%; (iii) household workers and retired persons, 20.2\%; and (iv) persons unable to work, $10.1 \%$.

The influence of occupation on the prevalence of diabetes was also analysed, after correcting for age, sex and BMI, in a multiple logistic regression analysis. Using manual labour as the reference category, only office jobs had a significant association with diabetes (OR, 3.04; $p=0.007)$.

Distribution of study subjects in the ascending quartiles of physical activity was $48.3 \%, 26.2 \%$, $22.8 \%$ and $2.8 \%$, quartile 1 being sedentary and quartile 4 being strenuous activity.

Table 3 shows a comparative profile of the results of the two rural surveys conducted in 1989 and 2003 in similar regions using identical methodology. Significant increases in anthropometric measurements were
Table 4. Results of the multiple logistic regression analysis

\begin{tabular}{lccc}
\hline Significant variables & OR & $95 \% \mathrm{CI}$ & $p$ value \\
\hline Age (years) & 1.05 & $1.03-1.06$ & $<0.0001$ \\
Sex (M:W) & 1.11 & $0.73-1.70$ & 0.626 \\
Waist (cm) & 1.38 & $1.23-1.54$ & $<0.0001$ \\
Sedentary physical activity $\left(\mathrm{PA}_{1}\right)$ & 1.65 & $1.03-2.64$ & 0.037 \\
Year: 1989 vs 2003 & 1.49 & $0.88-2.53$ & 0.137 \\
Constant & 0.5 & & -7.28 \\
\hline
\end{tabular}

$\mathrm{PA}_{1}$, physical activity, 1 st quartile etc; dependent variable: diabetes vs NGT; independent variables: age, BMI, waist, sex, categories of occupation, quartiles of physical activity, quartile $\mathrm{PA}_{4}$ was the reference; non-significant: sex, BMI, categories of occupation, year of testing, quartiles of physical activity $\mathrm{PA}_{2}$ and $\mathrm{PA}_{3}$

seen in both sexes. Prevalence of being overweight $\left(\mathrm{BMI} \geq 25 \mathrm{~kg} / \mathrm{m}^{2}\right)$ had increased significantly.

In the 2003 survey, women tended to confine themselves to household work, unlike in the previous survey in which women were also engaged in manual jobs. There were significant changes in the food habits, rice becoming a staple food in place of ragi, and vegetables and fat were included frequently in the diet. Two or more full meals per day were consumed by most subjects. In the previous survey, the meal consisted of only cereals and negligible quantities of proteins and fats.

Multiple logistic regression analysis combining the data of both studies (Table 4) showed that the increased prevalence of diabetes was associated with age $(\mathrm{OR}, 1.05 ; p<0.0001)$, waist circumference (OR, $1.38 ; p<0.0001)$ and a sedentary life style $(\mathrm{OR}, 1.65$; $p=0.037$ ).

Prevalence of IGT showed an association with age $(\mathrm{OR}, 1.75 ; p<0.0001)$ and $\mathrm{BMI}(\mathrm{OR}, 1.70 ; p<0.0001)$ in the present survey.

In the 1989 survey, only $24 \%$ of the diabetic subjects were known cases, while in the present survey, $60 \%$ were known cases.

\section{Discussion}

A comparison of the two rural surveys in southern India showed that the prevalence of diabetes had increased three-fold over a period of 14 years. The prevalence of IGT had remained unchanged.

Significant changes in lifestyle, including changes in food habits and reduction in physical activity, were apparent in the comparative analysis of the two surveys. The present study cohort had a higher prevalence of obesity. A significant association of upper body adiposity and a sedentary lifestyle was observed with the rising prevalence of diabetes.

Improvements in socio-economic conditions had occurred as shown by increased family income and 
improved educational status. The improved economic conditions were reflected in an increase in motorised transport and access to water and electricity. Fewer subjects were engaged in manual work $(22.8 \%$ in 2003 vs $80 \%$ in 1989). All these parameters had contributed to decreased energy expenditure in domestic as well as occupational functions.

It has generally been observed that there has been a remarkable shift in occupational structure in lower income countries from agricultural labour towards employment in manufacturing and services, resulting in a reduction in energy expenditure and a consequent increase in obesity [9].

We had previously noted that the risk of diabetes occurred at a lower BMI threshold $\left(<23 \mathrm{~kg} / \mathrm{m}^{2}\right)$ and central adiposity (waist circumference: men $85 \mathrm{~cm}$; women $80 \mathrm{~cm}$ ) in Asian Indians [10]. Therefore, the transition in lifestyle occurring in the rural population seemed to produce rapid adverse changes favouring diabetogenesis.

Prevalence of IGT had remained unchanged in the previous 14 years. The adverse environmental conditions could have favoured the conversion of IGT to diabetes, reducing the number of IGT subjects and increasing the number of diabetic subjects. The ratio of IGT:diabetes was approximately 1 . Prevalence of IGT was also higher in the younger rural Indian population, as in the urban population [2].

Awareness of the disease had increased with improved education, and access to medical care was also better. Therefore, $60 \%$ of the diabetic cases had already been diagnosed. Similar demographic changes owing to modernisation had been reported in several studies $[11,12,13]$.

Improvements in living conditions similar to those noted in our study were described in a neighbouring Bangladeshi population [11]. The prevalence of diabetes had increased from $2.23 \%$ to $3.8 \%$ in a period of 8 years. A prevalence of $6.5 \%$ for diabetes and $11.2 \%$ for IGT was reported in rural Pakistan in 1999 [12]. O'Dea et al. noted a significant increase in the prevalence of diabetes in Australian Aborigines consequent to regular contact with urbanised areas [13].

The present study showed that diabetes had increased three-fold over a span of 14 years in a rural population in southern India. The present burden of diabetes in developing countries is chiefly associated with the urban population. The lifestyle transition occurring in the rural areas could further add to this emerging epidemic.

Moreover, according to WHO estimates, the number of diabetic patients in India is underestimated considering the current rate of change in the rural population.

Acknowledgements. We thank all staff members who helped in conducting the screening, especially Ms Lalitha Manjula. Secretarial help from Ms A. Bobby is also acknowledged.

\section{Appendix I. Physical activity scoring system}

Categories of occupation

(i) Manual labourers (including masons, carpenters and those who carry loads, and agricultural work, e.g. ploughing and tilling)

(ii) Office jobs or desk work

(iii) Housewives and retired persons

(iv) Persons unable to work

Does your work involve mostly sitting/standing/walking?

Answer yes.

- Minimum score $=1$

Does your work involve moderate activity, e.g. brisk walking, fetching water from wells, moderate agricultural work, e.g. sowing seeds, weeding, painting buildings, household work etc?

Answer yes

- Score $=2(45 \mathrm{~min} /$ day $)$

- Score $=3(45-240 \mathrm{~min} /$ day $)$

- Score $=4(240-480 \mathrm{~min} /$ day $)$

- Maximum score $=28(4 \times 7$ days $/$ week $)$

Does your work involve vigorous manual activity (occupation category 1)?

Answer yes

- Score $=5(15-60 \mathrm{~min} /$ day $)$

- Score $=6(60-240 \mathrm{~min} /$ day $)$

- Score $=7$ (240-600 $\mathrm{min} /$ day $)$

- Maximum score $=49(7 \times 7$ days $/$ week $)$

Additional activities: Do you use a cycle or engage in sports activities?

Answer yes

- Score $=1(45 \mathrm{~min} /$ day $)$

- Score $=2$ (45-240 min/day)

- Score $=3$ (240-360 $\mathrm{min} /$ day $)$

- Maximum score $=21$ ( $3 \times 7$ days $/$ week $)$

Total $=70$

\begin{tabular}{lc}
\hline Quartiles of physical activity & \multicolumn{1}{c}{ Score } \\
\hline 1 Sedentary & $1-17$ \\
2 Light & $18-34$ \\
3 Moderate & $35-51$ \\
4 Strenuous & $>51$ \\
\hline
\end{tabular}




\section{References}

1. King H, Aubert RE, Herman WH (1998) Global burden of diabetes 1995-2025; prevalence, numerical estimates, and projection. Diabetes Care 21:1414-1431

2. Ramachandran A, Snehalatha C, Kapur A et al. (2001) For the Diabetes Epidemiology Study Group in India (DESI). High prevalence of diabetes and impaired glucose tolerance in India: National Urban Diabetes Survey. Diabetologia 44:1094-1101

3. Ramachandran A, Snehalatha C, Vijay V (2002) Temporal changes in prevalence of type 2 diabetes and impaired glucose tolerance in urban southern India. Diab Res Clin Prac 58:55-60

4. Mohan V, Shanthirani S, Deepa R, Premalatha G, Sastry NG, Saroja R (2001) Intra-urban differences in the prevalence of the metabolic syndrome in southern India-the Chennai Urban Population Study. Diabet Med 18:280-287

5. Misra A, Pandey RM, Ramadevi J, Sharma R, Vikram NK, Nidhi Khanna (2001) High prevalence of diabetes, obesity and dyslipidaemia in urban slum population of Northern India. Int J Obes 25:1-8

6. Ramachandran A, Snehalatha C, Daisy Dharmaraj, Viswanathan M (1992) Prevalence of glucose intolerance in Asian Indians: urban-rural difference and significance of upper body adiposity. Diabetes Care 15:1348-1355
7. Ramaiya KL, Kodali VR, Alberti KGMM (1990) Epidemiology of diabetes in Asians of the Indian Sub Continent. Diabetes Metab Rev 6:125-146

8. Alberti KGMM, Zimmet PZ, for the WHO Consultation (1998) Definition, diagnosis and classification of diabetes mellitus and its complications. Part 1: Diagnosis and classification of diabetes mellitus. Provisional report of a WHO Consultation. Diabet Med 15:539-553

9. Popkin BM (2001) Nutrition in transition: the changing global nutrition challenge. Asia Pac J Clin Nutr: S13S18

10. Snehalatha C, Vijay V, Ramachandran A (2003) Cut off values for normal anthropometric variables in Asian Indian adults. Diabetes Care 26:1380-1384

11. Abu Sayeed M, Mahtab H, Khanam PAA et al. (2003) Diabetes and impaired fasting glycemia in a rural population of Bangladesh. Diabetes Care 26:1034-1039

12. Shera AS, Rafique G, Khawaja IA, Baqai S, King H (1999) Pakistan National Diabetes Survey: prevalence of glucose intolerance and associated factors in Baluchistan province. Diab Res Clin Pract 44:49-58

13. O'Dea K, Patel M, Kubisch D, Hopper J, Traianedes K (1993) Obesity, diabetes, and hyperlipidemia in a Central Australian aboriginal community with a long history of acculturation. Diabetes Care 16:1004-1010 